\title{
Determining Optimum Anodic Oxidation Parameters for Hardness and Wear Properties of AA7075-T6 Alloys Using Taguchi Design
}

\author{
Samet YAVUZ ${ }^{1}, 2$, Yaşar SERT ${ }^{3}$, Mahmutcan KARSLI ${ }^{1},{ }^{3}$, Tevfik KÜÇÜKÖMEROĞLU ${ }^{3}$ \\ ${ }^{1}$ Girsan A.Ş., Giresun, Turkey \\ ${ }^{2}$ Department of Mechanical Engineering, On Dokuz Mayıs University, Samsun, Turkey \\ ${ }^{3}$ Department of Mechanical Engineering, Karadeniz Technical University, Trabzon, Turkey
}

\section{Keywords}

AA7075-T6,

Anodic Oxidation,

Hardness,

Wear Performance,

ANOVA

\begin{abstract}
In this study, the main goal is to determine the effects of the variable anodic oxidation process parameters on the hardness and wear properties of the AA7075-T6 alloy, which is widely used in the gun industry, automotive, aircraft, and space industry. Samples obtained using the process parameters designed by the Taguchi method were subjected to various experiments and the findings obtained from these experiments were compared with $S / N$ graphs determined using ANOVA analysis. As a result of these findings, it was determined that different coating thickness, hardness and wear resistance were obtained by varying the anodic oxidation process parameters. The highest oxide layer thickness obtained was determined as $70.63 \mu \mathrm{m}$. In addition, the oxide layer formed by the anodic oxidation process has significantly increased the hardness and wear resistance of the AA 7075-T6 alloy. Also, as a result of the experiments and ANOVA analysis, it was determined that the oxide layer obtained with the parameters of $22 \mathrm{~V}$ constant voltage, $1.3 \mathrm{~A} / \mathrm{dm} 2$ current density, $2^{\circ} \mathrm{C}$ temperature, 140 minutes of processing time will have the superior wear performance.
\end{abstract}

\section{Introduction}

A weapon is the tool used by humans for defense and hunting throughout history. Weapons fall into two categories, with and without fire. However, with the discovery of gunpowder, the use of firearms has become more common today. The firing mechanism in weapons takes place in the form of launching cartridges under the influence of propulsive force created by the expansion of the gas by the burning of gunpowder [1-3]. When considering firearms, small and portable ones usually come to the mind, but this term includes all types and sizes of guns, rifles, shotguns, and pistols. Among the firearms, the so-called light weapons, which are emphasized in this study are exposed to dynamic loads and the wear because of the gunpowder firing mechanism [4]. Technological advances in the history of this type of firearm are carried out in a direction that will ensure high resistance to plastic deformation and wear by prioritizing the lightness of them in terms of portability [5]. For this purpose, usually low cost, low specific weight, high strength and wear resistance are sought in the materials used in the production of firearms $[6,7]$. The gun frame that is one of the most important parts of light weapons is the part that is most exposed to wear due to cover on it and the working channels of the barrel. Due to these factors, AA 7075-T6 is widely used in terms of meeting the expected properties as gun frame and applicability of surface treatments. AA 7075 is a heat treatable aluminum alloy. Especially thanks to the heat treatment called $\mathrm{T} 6$, these alloys can be provided with high strength properties $[8,9]$. T6 heat treatment consists of artificial aging of the alloy after the solution treated and quenching. In this heat treatment, the solution process is carried out by keeping the alloy at $480^{\circ} \mathrm{C}$ for $1-2$ hours. After the quenching process, these alloys are artificially aged for one day at $120^{\circ} \mathrm{C}[10]$. The suitability of AA 7075-T6 alloys for the surface coating process has been determined with the developing technology. Also, it has been emphasized in the open literature that hardness and wear properties of these alloys are improved owing to these surface coatings [11]. For this goal, laser cladding, sol gel, anodic oxidation, plasma spray, cataphoresis coating and electrostatic painting have been used from past to present [12,13]. Among these methods, the anodic oxidation method is the process of forming the $\mathrm{Al}_{2} \mathrm{O}_{3}$ layer on the aluminum alloy surface by taking advantage of the high level of the oxide interest of aluminum [14]. The process of obtaining a homogenous $\mathrm{Al}_{2} \mathrm{O}_{3}$ layer on the surface of the aluminum in sulfuric acid solution by anodically electrolysis method is called "Anodic Oxidation". With this method, it has been determined that the surface hardness and resistance of wear of the aluminum alloys can be enhanced. Dejun et al. emphasized that dense oxide layer is formed on the surface of AA 7475 thanks to the anodic oxidation and owing to this the resistance to plastic deformation of the alloy is increased [15]. In another study, an oxide layer without any structural defects such as hillocks and cracks were obtained on the surface of AA 1050 alloy by anodic oxidation process. This oxide layer brought superior mechanical and wear properties such as high hardness, low coefficient of friction and high wear resistance in the alloy [16]. Besides, the effect of parameters in the anodic oxidation on the properties of the oxide layer is very important and should be examined. In a study carried out in this regard, 2024, 6082, and 7075 alloy samples were applied anodic oxidation process at different voltage and these effects were investigated. Anodic oxidation was performed at $12-22 \mathrm{~V}, 180 \mathrm{~g} / \mathrm{l}$ sulfuric acid for 25 minutes. It was stated that the highest thickness of the oxide layer was obtained at 18 V. When compared to the 6082 alloy, the alloys of 7075 and 2024 were observed to have less variation in thickness depending on the voltage. Also, it was determined that the highest hardness and wear resistance was obtained in the $\mathrm{Al}_{2} \mathrm{O}_{3}$ layer at $18 \mathrm{~V}$ [17]. However, it is striking that the number of studies examining the hardness and wear properties of the AA 7075 alloy of the anodic oxidation is rather limited. In order to overcome this deficiency in the open literature, this study investigated the formation of an oxide layer with anodic oxidation on the AA 7075 alloy surface and the hardness and wear properties of this layer compared to the untreated alloy. In addition, the parameters such as current, temperature and time used in the anodic oxidation were applied as variables, and the effects of these parameters on the properties of the oxide layer were quantified by ANOVA analysis. In this way, the findings and approaches revealed as results of this study
${ }^{*}$ Corresponding Author: yasarsert@ktu.edu.tr

(Y. Sert Orcid: 0000-0001-7742-0335) 
will be a significant guide for the researchers who will work on this matter.

\section{Material and Method}

\subsection{Preparations of Samples}

In this study, cold forged AA7075-T6 ( $\mathrm{Zn} \sim 5.8 \%, \mathrm{Mg} \sim 2.4 \%, \mathrm{Cu} \sim 1.5 \%$, $\mathrm{Fe}-0.24 \%, \mathrm{Cr}-0.2 \%$, Si $-0.08 \%$ ) aluminum alloys which are commercially used a gun frame material were purchased from the market. The purchased AA7075-T6 alloys were prepared in the dimensions $\left(50 \times 50 \times 10 \mathrm{~mm}^{3}\right)$ determined for examinations prior to the anodic oxidation process. Subsequently, the surfaces of alloys were grounded (400-600-800-1200 $\mu \mathrm{m}$ mash) and sandblasted by $\mathrm{Al}_{2} \mathrm{O}$ particles with size of $120 \mu \mathrm{m}$. The samples obtained after metallographic processes are given in Figure 1.

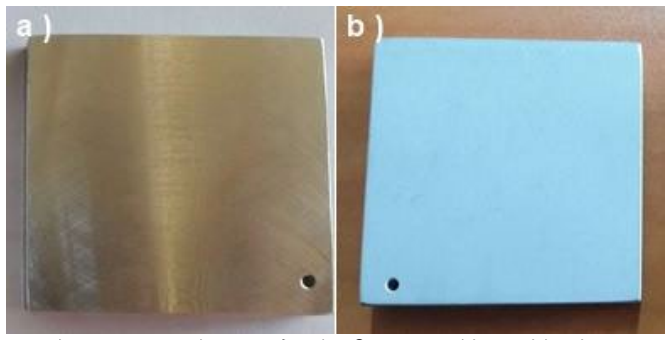

Figure 1. The prepared samples before anodic oxidation process a) Grinding b) Sandblasting

\subsection{Anodic Oxidation Process}

The samples were subjected to degreasing, etching and neutralization processes and then their surfaces were cleaned from residues such as dirt-oxide before the oxidation process. In the degreasing process, the oils on the sample surfaces were removed for 10 minutes in the bath with a water-based solution at $60-70^{\circ} \mathrm{C}$ the etching process was carried out for 4 minutes in $4 \% \mathrm{NaOH}$ bath at $40-50^{\circ} \mathrm{C}$. Then, the samples were subjected to neutralization in $20 \%$ nitric acid $\left(\mathrm{HNO}_{3}\right)$ for 5 minutes to remove the black spots formed by etching on the surfaces of the AA7075-T6 alloys. The schematic of this process is shown in Figure 2 .

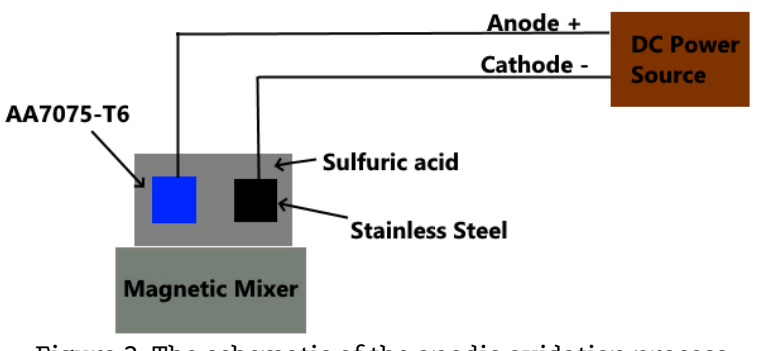

Figure 2. The schematic of the anodic oxidation process

In the oxidation process which is also seen in the schematic, stainless steel was as the cathode, and AA 7075-T6 samples were used as the anode. $180 \mathrm{~g} / 1 \mathrm{H}_{2} \mathrm{SO}_{4}$ (purity $96 \%$ ) was used as an oxidation solution. In this process, the voltage was kept constant at $22 \mathrm{~V}$ and the current density, temperature and time were used as variables. Variable parameters were designed by using the Taguchi method to quantify the effects of the variable parameters on the properties of the oxide layer. This design determined as 3 variables and 4 levels is given in Table 1.

Table 1. The design of the parameters of the anodic oxidation process

\begin{tabular}{cccc}
\hline & $\begin{array}{c}\text { Current } \\
\text { Density } \\
\left(\mathrm{A} / \mathrm{dm}^{2}\right)\end{array}$ & Temperature $\left({ }^{\circ} \mathrm{C}\right)$ & $\begin{array}{c}\text { Time } \\
(\mathrm{min} .)\end{array}$ \\
\hline Samples & Level 1 & Level 2 & Level 3 \\
\hline N1 & 0.9 & -2 & 140 \\
N2 & 0.9 & 0 & 170 \\
N3 & 0.9 & 2 & 190 \\
N4 & 0.9 & 4 & 210 \\
N5 & 1.1 & -2 & 170 \\
N6 & 1.1 & 0 & 140 \\
N7 & 1.1 & 2 & 210 \\
N8 & 1.1 & 4 & 190 \\
N9 & 1.3 & -2 & 190 \\
N10 & 1.3 & 0 & 170 \\
N11 & 1.3 & 2 & 190 \\
N12 & 1.3 & 4 & 210 \\
N13 & 1.5 & -2 & 140 \\
N14 & 1.5 & 0 & 170 \\
N15 & 1.5 & 2 & 190 \\
N16 & 1.5 & 4 & 210 \\
\hline
\end{tabular}

The surface morphology of the anodized samples was examined by the Zeiss scanning electron microscope (SEM). The surface roughness of the untreated and anodized samples was determined using a Nanofocus brand optical profilometer. The oxide thickness of the samples was measured with the help of an optical microscope. Struers brand Vickers micro-hardness tester was used for measurements of the hardness. Average micro-hardness of untreated and anodic oxidation treated samples were determined by performing 5 measurements at $10 \mathrm{~s}$ of dwell time under $25 \mathrm{~g}$ constant load. Ducom computer-controlled ball-on disc wear tester was used to determine the tribological properties of the samples. The wear test parameters are given in Table 2 . The number of cycles has been determined as 10.000 cycles to obtain twice the desired repetition in the 5,000 stroke strength tests required in the tender specifications of the weapon.

Table 2. Wear Test Parameters

\begin{tabular}{lc}
\hline Parameters & \\
\hline Constant load & $5 \mathrm{~N}$ \\
Counter body & $\mathrm{Al}_{2} \mathrm{O}_{3}$ \\
Number of cycles & 10000 \\
Sliding distance & $597 \mathrm{~m}$ \\
Track diameter & $19 \mathrm{~mm}$ \\
Cycle speed & $300 \mathrm{rev} / \mathrm{min}$ \\
\hline
\end{tabular}

\section{Results and Discussion}

SEM images of sample surfaces before and after anodic oxidation are shown in Figure 3. It is seen that the oxide layer has a porous structure. I.e., at the beginning of the anodic oxidation process, a thin and non-porous barrier oxide layer is formed. This barrier oxide layer, which reaches its greatest thickness after 4- 5 seconds begins to erode under constant voltage with the influence of the temperature and electrolyte. With increasing thickness of the oxide layer around the these wearing areas, channels and cavities are consisted of. These channels and cavities provide the formation of areas that allow electrical current to pass through the samples. As a result of this, ions move from these areas to form the characteristic porous structure of the oxide layer $[18,19]$. It has been determined that these pores substantially affect the roughness of the oxidized surfaces. In this figure, it is clearly seen that the surfaces of the oxidized samples rougher. However, under some oxidation conditions, micro-level cracks have been encountered. These micro-cracks caused the oxide layer to separate from the surface occasionally. 

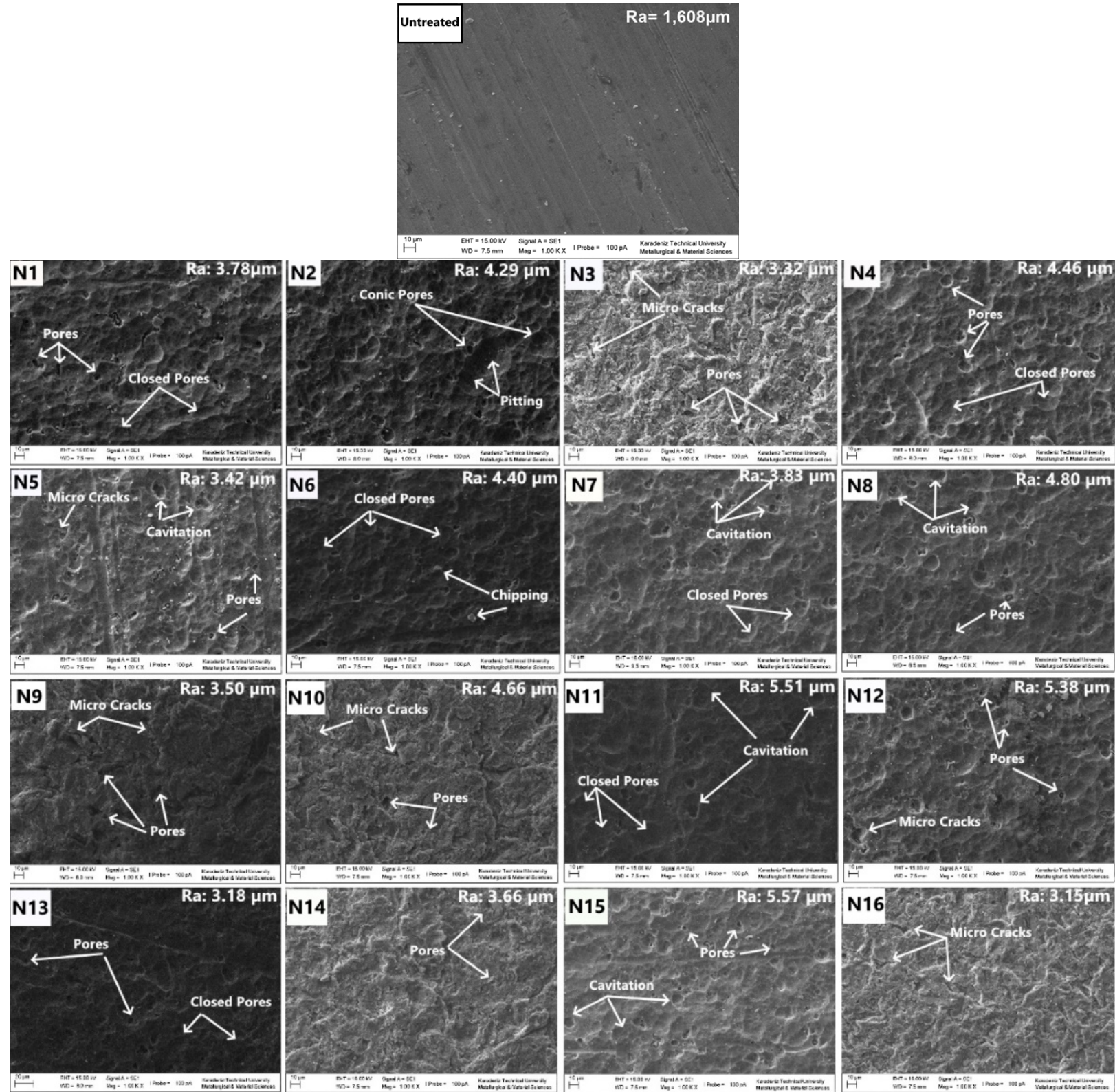

Figure 3. The SEM images of the sample surfaces

Cross-section morphologies of oxide layers are shown in Figure 4. The average oxide layer thickness values of samples are given in Table 3 . As can be seen from Table 3, different oxide layer thicknesses were obtained under different oxidation conditions. The lowest oxide layer thickness is determined from the N16 oxidation condition as $51.66 \mu \mathrm{m}$ and the highest oxide layer thickness is obtained from the $\mathrm{N} 13$ condition as $70.63 \mu \mathrm{m}$. As a result of the statistical investigations, $\mathrm{S} / \mathrm{N}$ ratio charts are given in Figure 5 . According to this figure, ANOVA analysis shows that the most influential parameter on the oxide layer thickness is temperature (41.45\%). Studies in which similar findings are obtained have been encountered in the open literature. Tsangaraki et al. were reported that as a result of increasing the temperature under constant voltage, the coating thickness decreased due to the acceleration of the dissolution of the aluminum oxide layer from the surface [20]. Li et al. emphasized that in the anodic oxidation process conducted on the Al-Si alloys, the lowest oxide thickness was achieved at high temperatures [21]. In another study, as a result of Bozza et al. examining the effect of different current density, they found that the increased process temperature in anodic oxidation processes performed at constant time and current density caused the oxide layer thickness to decrease [22].

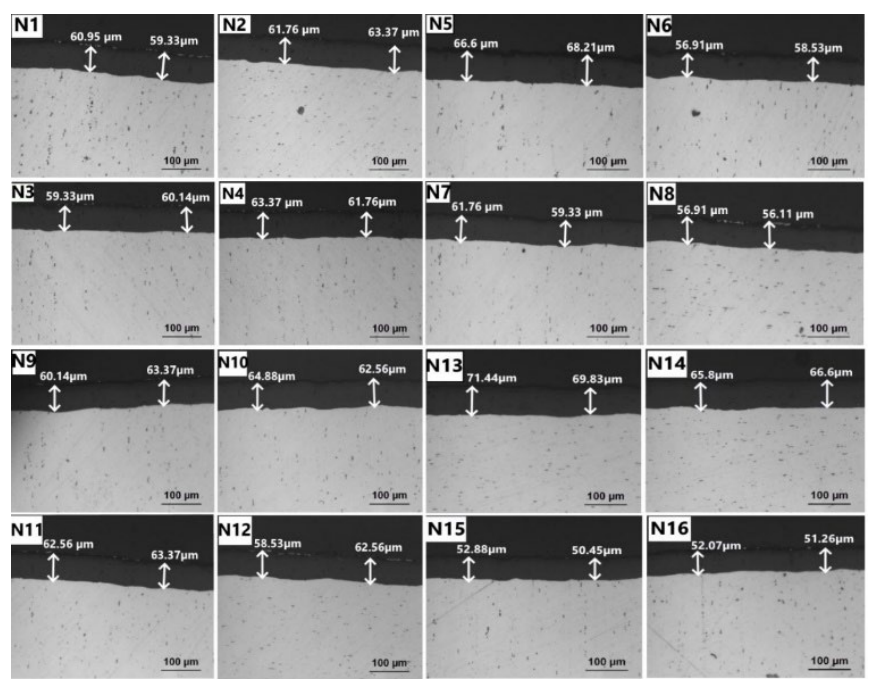

Figure 4. The oxide thickness obtained in the samples 
Table 3. The average thickness of oxide layers

\begin{tabular}{cccccccc}
\hline \multicolumn{8}{c}{ Average Thickness $(\mu \mathrm{m})$} \\
\hline N1 & 60.14 & N2 & 62.66 & N3 & 59.73 & N4 & 62.56 \\
N5 & 67.43 & N6 & 57.72 & N7 & 60.54 & N8 & 56.51 \\
N9 & 61.75 & N10 & 63.72 & N11 & 62.96 & N12 & 60.54 \\
N13 & 70.63 & N14 & 66.2 & N15 & 51.66 & N16 & 51.66 \\
\hline
\end{tabular}

The micro hardness values of the anodized samples are shown in Figure 6. When compared to the untreated sample, it is determined that the surface hardness increases with all the anodic oxidation conditions. The hardness value of the untreated material is 158 $\mathrm{HV}_{0.025}$. The superior hardness values of oxide layers are obtained as $389 \mathrm{HV}_{0.025}$ from the N11 condition.

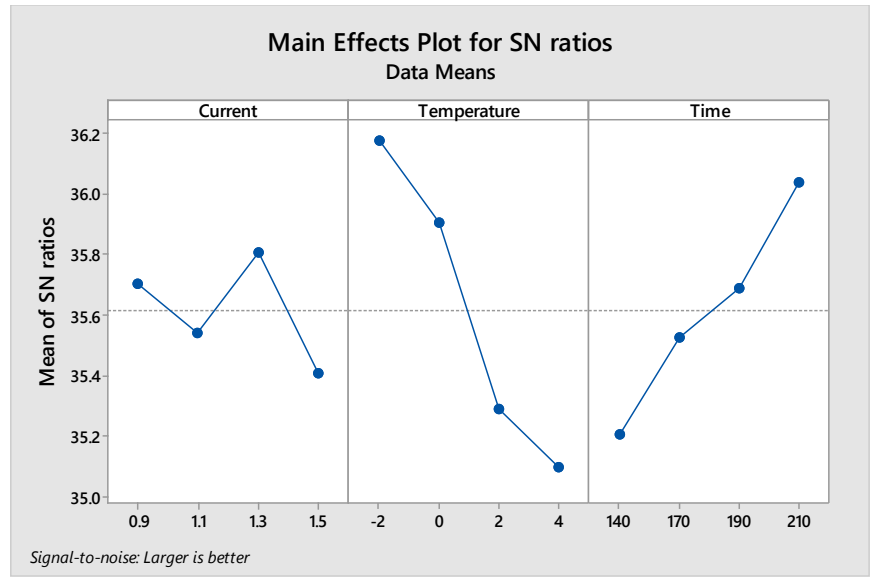

Figure 5. The charts of the effect of oxidation parameters on the oxide thickness

According to Figure 7, ANOVA analysis shows that the most influential parameter on the oxide layer thickness is the temperature (34.87\%). According to the results, an increase of at least $100 \%$ is observed in the hardness values of the oxidized samples compared to the untreated sample. As a result of the statistical investigations, S/N ratio charts are given in Figure 8 . It is determined that the hardness of the oxide layer increases as the current density and process temperature increase. superior resistance of wear [23,24].

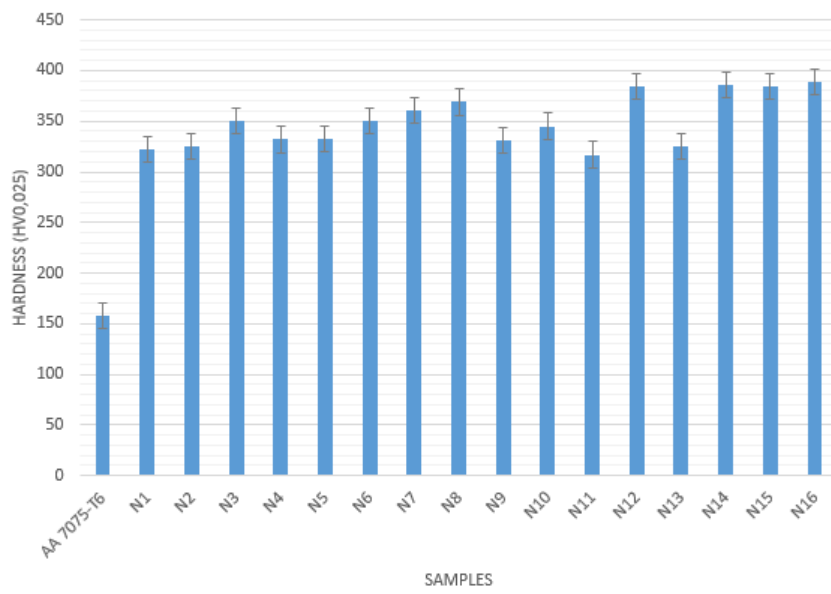

Figure 6. Comparative graph of the hardness values

The highest hardness value is obtained from the N16 condition that is performed with the highest temperature, and this result coincides with ANOVA analysis. In the anodic oxidation carried out at low temperatures, the effect of high temperature in the current passage is eliminated by the cooling effect of the electrolyte. The high voltage applied to achieve high current density at low temperatures provide small size, dense porous microstructure and uniform oxide layer, resulting in harder and the coefficient of friction (COF) graphs recorded during wear experiments are given in Figure 8. According to this figure, regardless of the applied load, the untreated sample has a lower COF than oxidized samples. The oscillations in the graphs have occurred because of the particles breaking off from the surface between the counter body $\left(\mathrm{Al}_{2} \mathrm{O}_{3}\right.$ ball) and the sample surface. It is determined that, this oscillation is more distinct in the untreated sample. When the average COF value is examined, it is seen that the value closest to the untreated sample is obtained as 0.48 from the N6 oxidization condition. The highest average COF value is determined as 0.6 under the N15 oxidization condition. The reason for this increase in the average $\mathrm{COF}$ is thought to be the increasing of the roughness of surface with anodic oxidation. In this context, there are some studies with similar findings in the open literature.

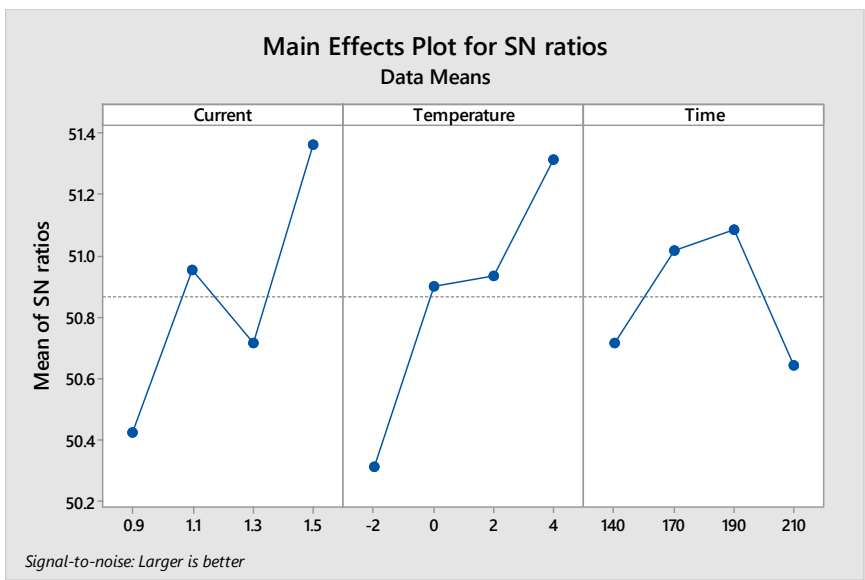

Figure 7. The charts of the effect of oxidation parameters on the hardness

Kim et al. emphasized that the oxidization process enhances the average $\mathrm{COF}$ values of the substrate material when examining the wear properties of nanoporous aluminum oxide films [25]. S/N graphs obtained as a result of the statistical investigations carried out to determine the effect percentages of the oxidization parameters on the average COF values are given in Figure 10. According to the analysis, it is determined the current was the most influential parameter on the average COF values with $74.91 \%$. The effect percentages of the time and temperature were determined to be $16.21 \%$ and $1.7 \%$ respectively. In a related study, it was stated that the surface roughness and $\mathrm{COF}$ values decreases at high anodic current densities although the COF of the oxide layers obtained at different voltages is close to each other.

Optical profilometer images of wear tracks obtained from wear experiments are shown in Figure 10. In the examinations carried out on these images, the wear volumes of the samples are determined and given comparatively in Figure 11. According to Figure 11, the highest wear volume is determined in the untreated sample as $4.28 \mathrm{~mm}^{3}$. Owing to the oxide layer on the surface, the volume of wear is decreased in oxidized samples compared to the untreated one. Among the samples which are carried out anodic oxidation process, the lowest wear volume is found out under N11 condition as $2,09 \times 10^{-2}$ $\mathrm{mm}^{3}$. The reason for this can be related with the denser structure and less superficial defects compared to the others. S/N graphs obtained as a result of the statistical examinations carried out to determine the most effective parameter on the wear volumes of the samples are given in Figure 12. As can be seen in this figure, the percentage of effects of the parameters on the wear volumes are almost similar. Although there are minor differences, the superior effective parameter is the anodization processing time with $28.12 \%$. 

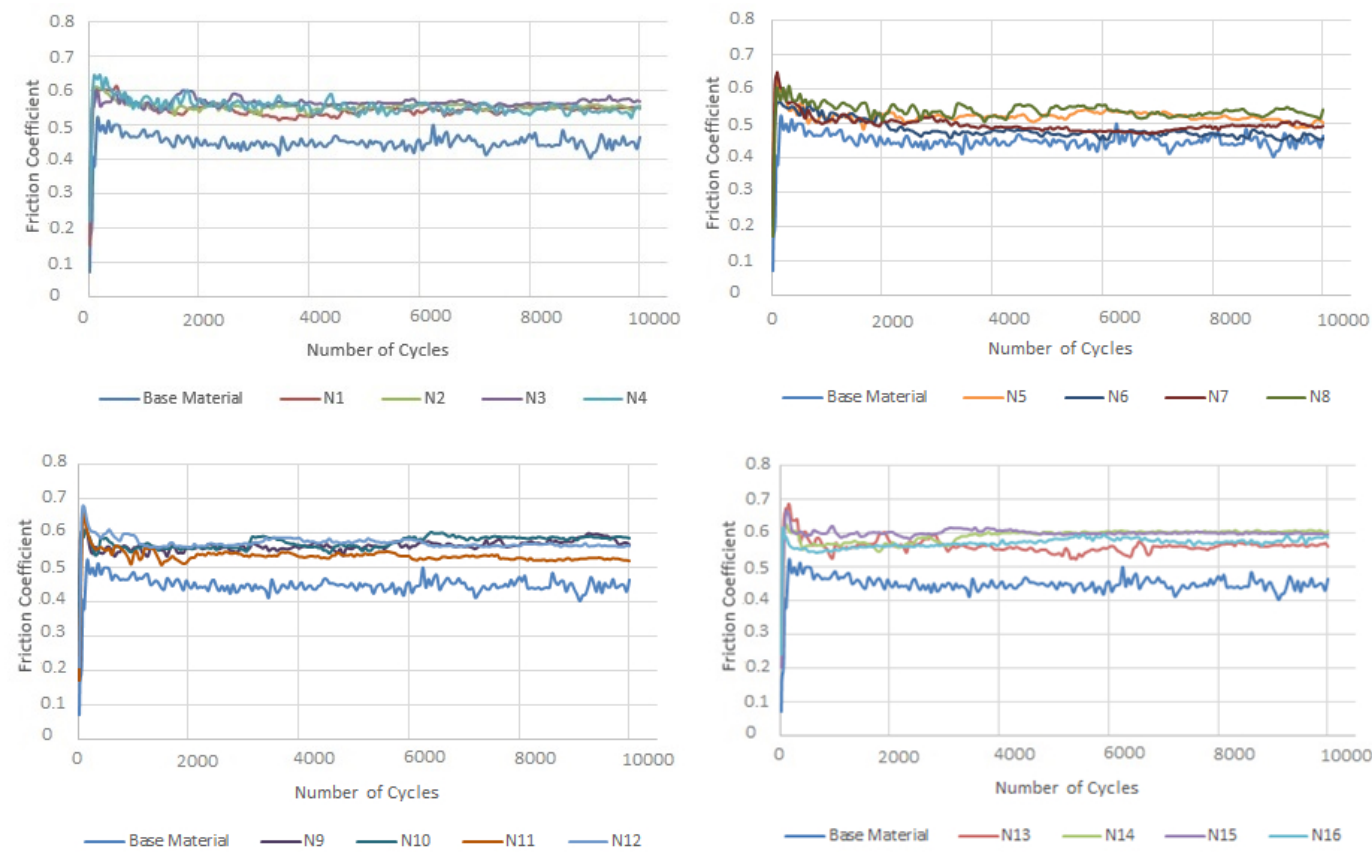

Figure 8. The COF- Cycles graphs for the tribological pairs

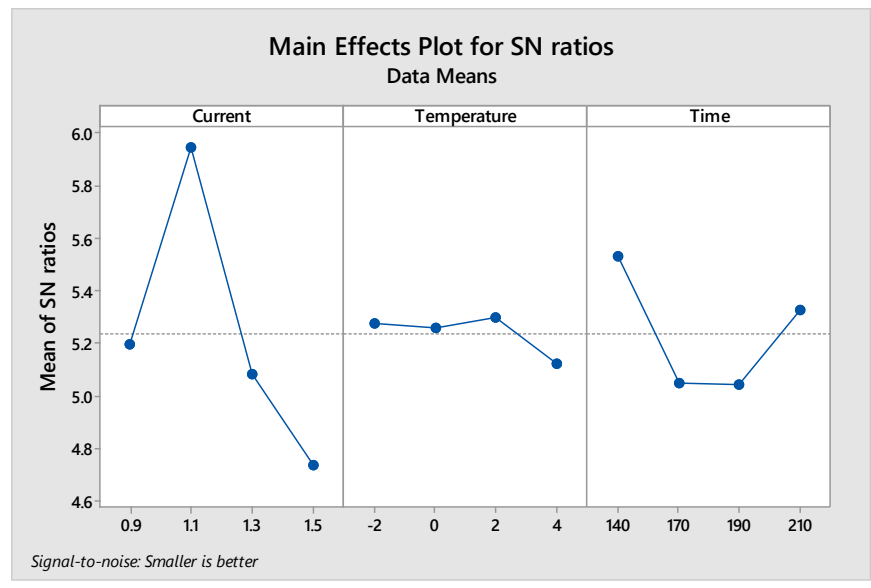

Figure 9. The charts of the effect of oxidation parameters on the COF values

It is determined that the wear volume is relatively less in samples such as $\mathrm{N} 1$ and $\mathrm{N} 6$ which the anodic oxidation is performed for the shortest time (140 $\mathrm{min}$.). In addition, the highest wear performance is achieved after N11 in the anodization process at $1.5 \mathrm{~A}$ current value. According to these findings, it can be interpreted that the wear performance of the oxidized samples at high currents and low process time was superior. One of the possible reason for this is that the samples in the current density group of $1.5 \mathrm{~A} / \mathrm{dm}^{2}$ have higher surface hardness than the low current density groups. It has been manifested in the open literature that the materials with high hardness i.e., high resistance to plastic deformation have great wear resistance [20]. Besides, it has been determined that samples with high wear performance have lower surface roughness. There are some studies in the literature that support the findings obtained in this study. Krishna et al. reported that owing to the anodic oxidation process enhanced the hardness of substrate material (AA6061-T6) and that the volume loss was significantly reduced with increasing hardness [26]. Li et. al. emphasized that the highest wear resistance was achieved at high current density values and low process time in the anodic oxidation process $[27]$

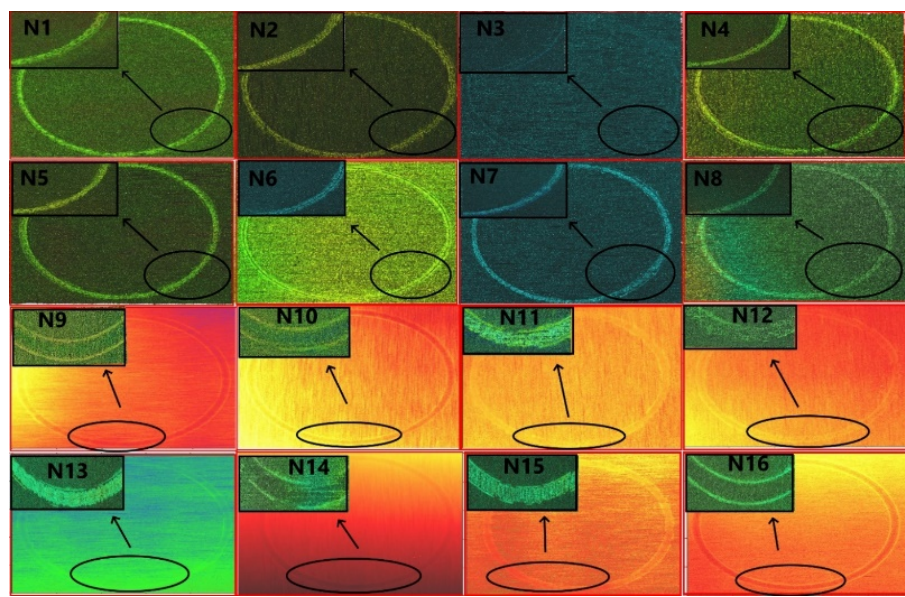

Figure 10. Optical profilometer images of wear tracks

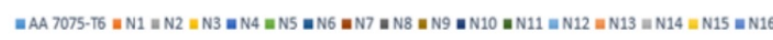

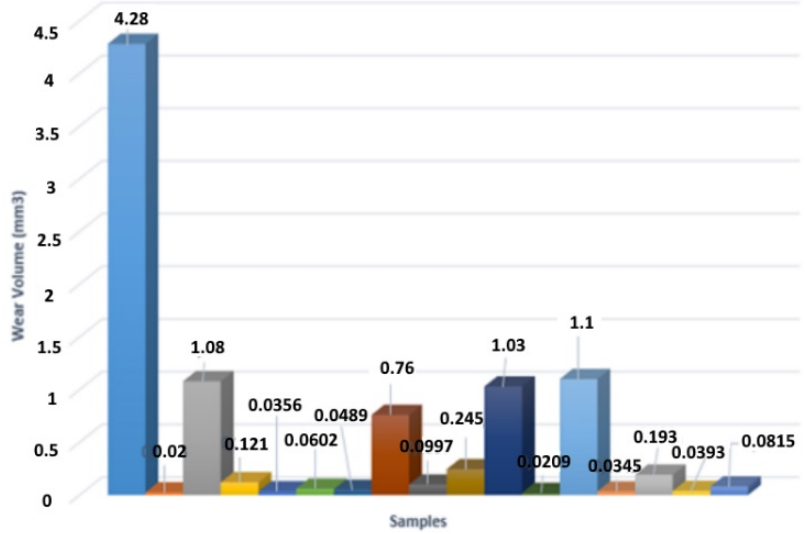

Figure 11. Comparative graph of the wear volumes of samples 


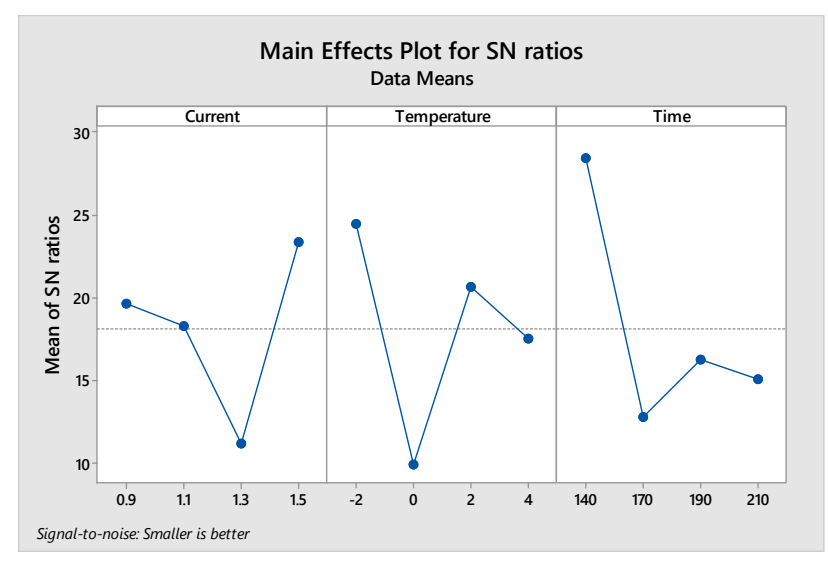

Wear tracks of untreated and oxidized samples are given in Figure 13 (a-b). From the wear track of the untreated sample, it is seen that the oxide layer has been removed from the surface due to adhesive wear. On the other hand, due to the higher hardness in oxidized samples, the broken micro-welds cause scraping effect on the surface. These ruptured particles entering between the surface and the counter body cause third body effect.

Figure 12. The charts of the effect of oxidation parameters on the wear volume

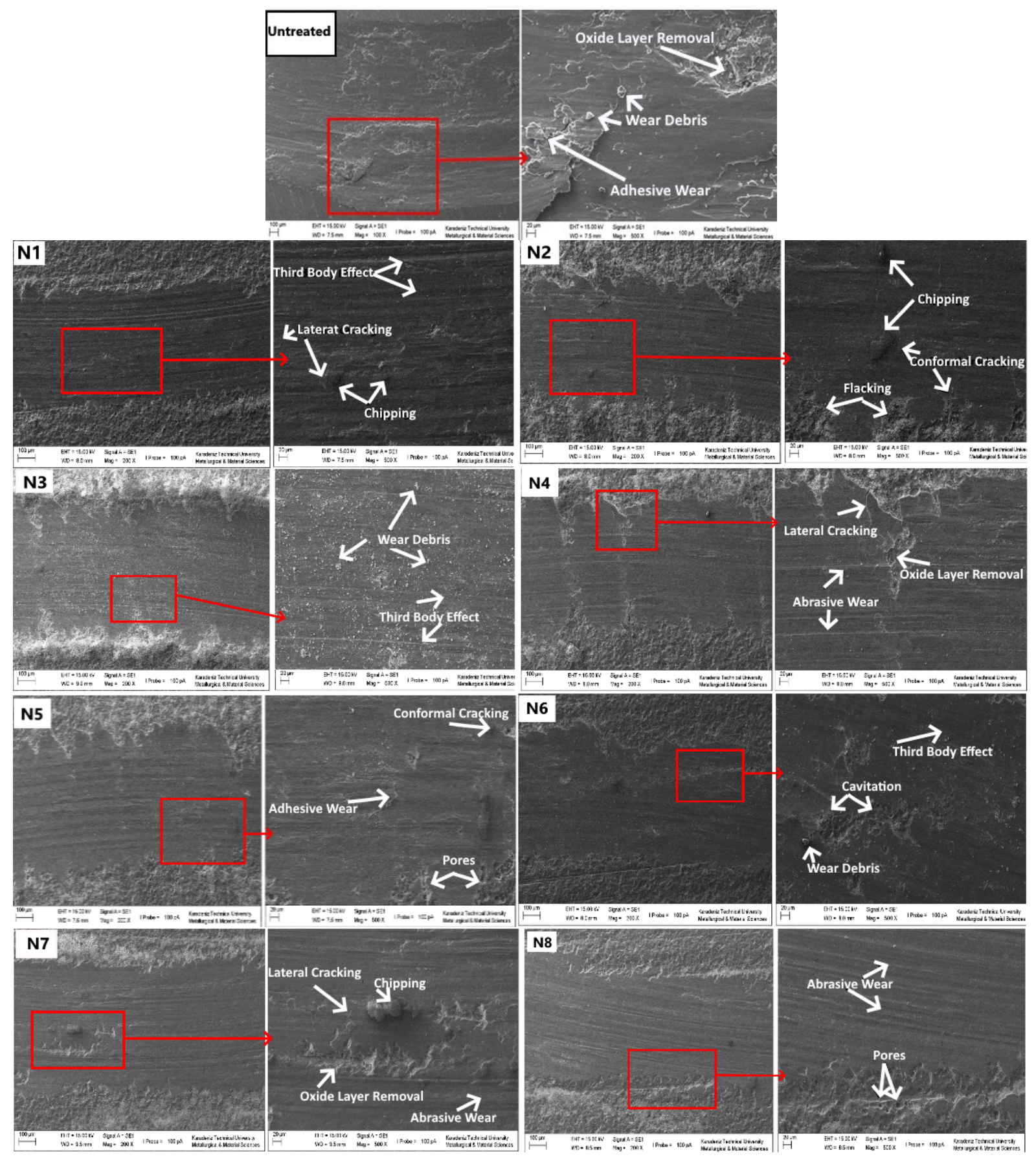

Figure 13-a. The SEM images of the wear tracks (Untreated and N1-N8) 

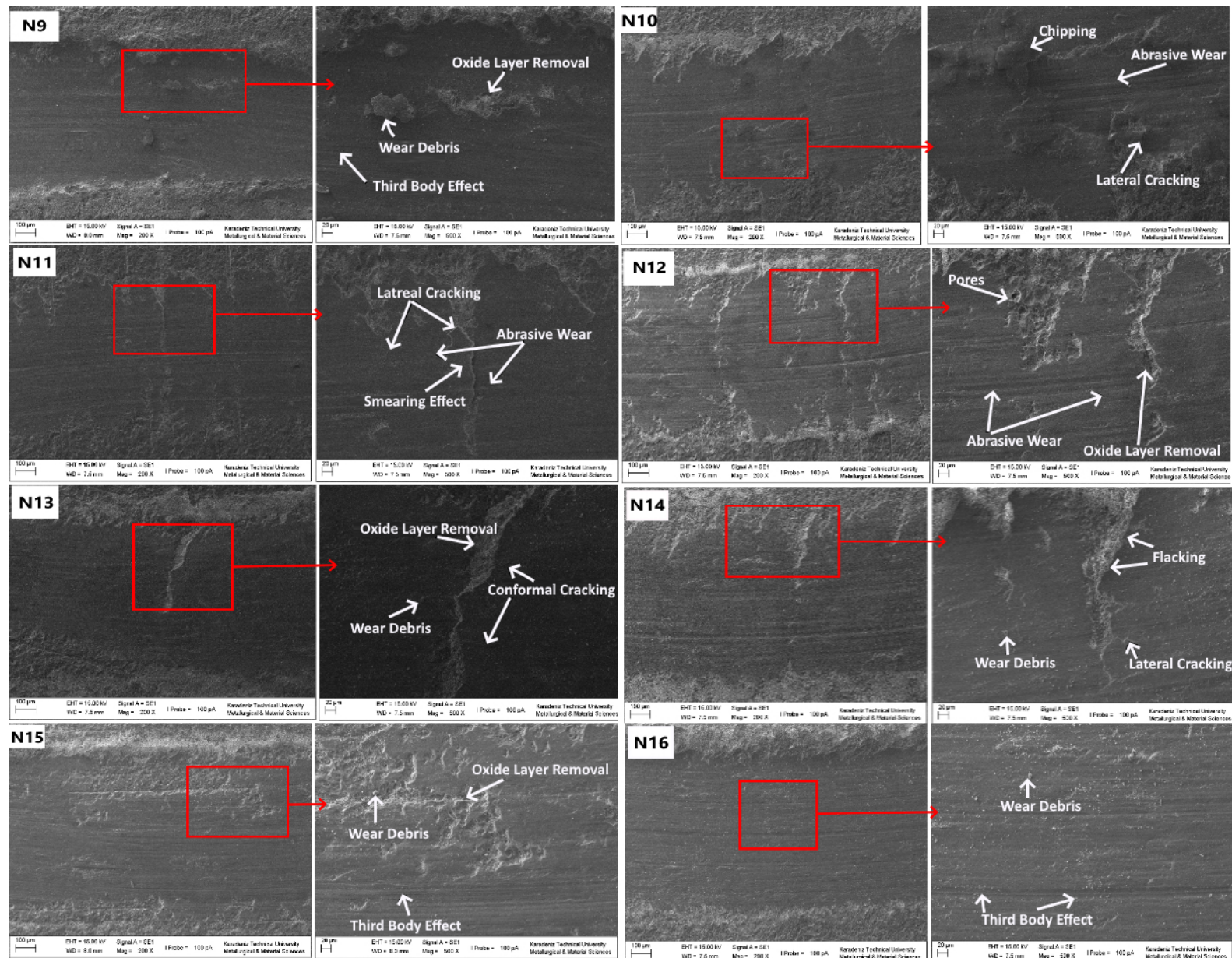

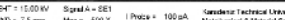
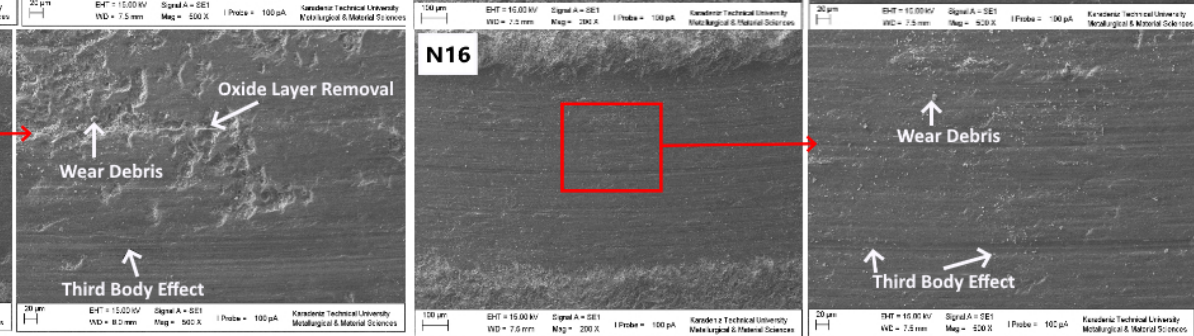

Figure 13-b. The SEM images of the wear tracks (N9- N16)

\section{Conclusion}

In this study, the anodic oxidation process was performed on the surface of AA7075-T6 alloy, which is used as a gun frame material in the industry. This process was designed according to the L16 orthogonal sequence with the Taguchi method by using the current, temperature and time as variable process parameters. The surface properties, oxide layer thickness, hardness and wear performance of the anodized alloys were determined, and the effects of variable parameters on these properties were quantified by ANOVA analysis. The related results are as follows.

- Nano scaled pores are formed on the AA7075 alloys surface with anodic oxidation.

- The oxide layer produced with the selected process parameters increased the surface roughness of the substrate material.

- The most effective parameter on the thickness of the oxide layer is the processing time. The least effective parameter is the current density.

- The hardness values of the oxide layer increased with raising anodic oxidation temperature and current.

- Anodic oxidation process increased the average COF and wear resistance of the AA7075-T6 alloy.

- While the COF is most directly affected by the oxidation current, it is least affected by temperature.

- Keeping the processing time low in addition to the enhancing current density in oxidation process improved the wear resistance of alloys.

- In the 7075-T6 alloy to be used for the manufacture of the gun frame, the superior wear resistance is obtained in the $1.3 \mathrm{~A} / \mathrm{dm}^{2}$ current density, $2^{\circ} \mathrm{C}$ temperature, and $140 \mathrm{~min}$ processing time.

\section{Declaration of Conflict of Interests}

The authors declare that there is no conflict of interest.

\section{References}

[1.] Liu, J., Riyanto, Y. E., Zhang, R., Firing the right bullets: Exploring the effectiveness of the hired-gun mechanism in the provision of public goods, Journal of Economic Behavior and Organization, 170 (2020) 222-243.

[2.] Andreoni, J., Gee, L. K., Gun for hire: delegated enforcement and peer punishment in public goods provision, Journal of Public Economics, 96 (11-12) (2012) 1036-1046.

[3.] Chugh, O. P., Mathematical analysis of dispersion of pellets fired from a shot gun, Forensic Science International, 32 (2) (1986) 93102

[4.] Aksoy, O. C., Functions and uses of metallic axe-heads and arrowheads from Safah, Oman: An analysis of metalwork wear and weapon design, Journal of Archaeological Science: Reports, 19 (2018) 727-752.

[5.] Sadowski, R. A., Gun Trader's Guide, Fortieth Edition: A Comprehensive, Fully Illustrated Guide to Modern Collectible Firearms with Current Market Values Paperback, 2018.

[6.] Engel, D. R., The Truth About Firearms and Concealed Carry 2014.

[7.] Monturo, C., Chapter 5 - Firearm manufacturing techniques, Forensic Firearm Examination, (2019) 75-142.

[8.] Sreenivasan, S., Mishra, S. K., Dutta, K., Ratcheting strain and its effect on low cycle fatigue behavior of Al 7075-T6 alloy, Materials Science and Engineering: A, 698 (2017) 46-53.

[9.] Huo, W., Hou, L., Zhang, Y., Zhang, J., Warm formability and postforming microstructure/property of high-strength AA 7075-T6 $\mathrm{Al}$ alloy, Materials Science and Engineering: A, 675 (2016) 44-54. 
[10.] Mahathaninwong N., Plookphol, T., Wannasin, J., Wisutmethangoon, S., T6 heat treatment of rheocasting $7075 \mathrm{Al}$ alloy, Materials Science and Engineering: A, 532 (2012) 91-99.

[11.] Liu, X., Fakir, O. E., Gharbi, M. M., Wang, L., Effect of tool coating on interfacial heat transfer coefficient in hot stamping of AA7075 aluminum alloys, Procedia Manufacturing, 15 (2018) 1127-1133.

[12.] Costenaro, H., Lanzutti A., Paint, Y., Fedrizzi, L., Terada, M., de Melo, H. G., Oliver, M.-G., Corrosion resistance of $2524 \mathrm{Al}$ alloy anodized in tartaric-sulphuric acid at different voltages and protected with a TEOS-GPTMS hybrid sol-gel coating, Surface and Coatings Technology, 324 (2017) 438-450.

[13.] Bayrak, O., Asl, H. G., and Ak, A., Protein adsorption, cell viability and corrosion properties of Ti6Al4V alloy oxidized by plasma and anodic oxidation, Int. J. Miner. Metall. Mater. https://doi.org/10.1007/s12613-020-2020-5

[14.] Bruera, F. A., Kramer, G. R., Vera, M. L., Ares, A. E., Evaluation of the influence of synthesis conditions on the morphology of nanostructured anodic aluminum oxide coatings on $\mathrm{Al} 1050$, Surfaces and Interfaces, 18 (2020) 100448.

[15.] Dejun, K., Jinchun, W., Hao, L., Friction and Wear Performances of 7475 Aluminium Alloy after Anodic Oxidationi Rare Metal Materials and Engineering, 45 (5) (2016) 1122-1127.

[16.] Remesova, M., Tkachenko, S., Kvarda, D., Rocnakova, I., Gollas, B. Menelaou, M., Celko, L., Kaiser, Z., Effects of anodizing conditions and the addition of $\mathrm{Al}_{2} \mathrm{O}_{3}$ /PTFE particles on the microstructure and the mechanical properties of porous anodic coatings on the AA1050 aluminium alloy, Applied Surface Science, 513 (2020) 145780.

[17.] Sismanoglu, T., Improvement of surface properties of 2024, 6082 and 7075 aluminum alloys by anodic oxidation, Master Thesis, Istanbul Technical University, 2009.

[18.] Dong, H., Surface Engineering of Light Alloys, Woodhead Publishing, New York, 2010.

[19.] Carabolante, J. P. A., da Silva, K. C., Chaves, J. A. M., Netipanyj, M. F. D., Popat, K. C., Claro, A. P. R. A., Nanoporous layer formation on the Ti10Mo8Nb alloy surface using anodic oxidation, Surface and Coatings Technology, 386 (2020) 125467.

[20.] Tsangaraki-Kaplanoglou, I., Theohari, S., Dimogerontakis, Th., Wang, Y-M., Kuo, H-H., Kia, S., Effect of alloy types on the anodizing process of aluminum, Surface and Coatings Technology, 200 (8) 2006, 2634-2641.

[21.] Li, X., Nie, X., Wang, L., Northwood, D. O., Corrosion protection properties of anodic oxide coatings on an Al-Si alloy, Surface and Coatings Technology, 200 (5-6) (2005) 1994-2000.

[22.] Bozza, A., Giobanardi, R., Manfredini, T., Mattioli, P., Pulsed current effect on hard anodizing process of 7075-T6 aluminium alloy, Surface and Coatings Technology, 270 (2015) 139-144.

[23.] Henley, W. F., Anodic Oxidation of Aluminium and Its Alloys, Pergamon Press, England, 1981.

[24.] Poyner, J., Electroplating, Workshop Practise Series Number 11, Argus Books, England, 1991.

[25.] Kim, H-S., Kim, D-H., Cho, S. J., Hahn, J-H., Ahn, H-S., Tribological properties of nanoporous anodic aluminum oxide film, Surface and Coatings Technology, 205 (5) (2010) 1431-1437.

[26.] Krishna, L. R., Purnima, A. S., Sundararajan, G., A comparative study of tribological behavior of microarc oxidation and hardanodized coatings, 261 (10) (2006) 1095-1101.

[27.] Li, Q., Liang, J., Liu, B., Peng, Z., Wang, Q., Effects of cathodic voltages on structure and wear resistance of plasma electrolytic oxidation coatings formed on aluminum alloy, Applied Surface Science. 297 (2014) 176-181.

\section{How to Cite This Article}

Yavuz, S., Sert, Y., Karsli, M., and Küçükömeroğlu, T., Determining Optimum Anodic Oxidation Parameters for Hardness and Wear Properties of AA7075-T6 Alloys Using Taguchi Design, Brilliant Engineering, 1(2021), 10-17. 